\title{
Research on the Application of Interactive Teaching Model in College English Writing
}

\author{
Qiong Peng \\ School of Foreign Languages, Wuhan Textile University, Wuhan, 430073, China \\ email: lily_hoo@126.com
}

Keywords: Interactive Teaching Model; English Writing; College Students

\begin{abstract}
The teacher-centered teaching model is prevalent in traditional English writing class. However, this one-way teaching model often focuses on results but neglects teaching process, which makes it difficult for teachers to arouse students' interests. This study applies interactive teaching to college English writing classes to explore the impacts of interactive teaching on college English writing. This study firstly analyzes teachers' puzzles and difficulties in teaching college English writing, then outlines the interactive teaching model, and finally discusses the application of interactive teaching model in college English writing teaching. This paper suggests that the interactive teaching model aims at developing the pragmatic competence of language learners; through teacher-student interaction and student-to-student interaction, learners' main status can be established, and autonomous learning, exploration learning and cooperative learning can be truly realized, thereby effectively improving their comprehensive ability of language use.
\end{abstract}

\section{Introduction}

Writing has always been the most neglected link in the four major skills of listening, speaking, reading and writing in English teaching of China. [1] As a language output skill, writing can not only achieve the purpose of language use, but also reflect the capacity of learners. Therefore, writing plays an important role in the teaching of English. However, traditional teaching model of English writing is usually centered by the teacher, attaching great importance to the results instead of the process of writing. [2] Different from the traditional mode, interactive teaching model emphasizes interaction and cooperation in the classroom, providing more extensive research ideas for the teaching of English writing.

\section{Problems and Confusion in the Teaching of English Writing}

As a comprehensive intellectual activity, writing is a thought-based art with language as its tool. It requires not only rich imagination, but also logical thinking of language and insightful thought. Nowadays, three things are very common in teaching of English writing: (1) students have great trouble in English writing, and teachers are also not willing to teach writing; (2) teachers feel disappointed about students' slow progress; (3) students lack proper guidance, and teachers need proper teaching principle and methods. For students, the main factors that lead to difficulties in English writing can be divided into four aspects: language barriers, the influence of thinking mode formed in mother tongue, the lack of capability of thinking and expression, and insufficient writing knowledge and skills. Every teacher has a longing to achieve diversified forms in teaching, enhance the efficiency and coverage of feedback, and improve students' enthusiasm in English writing.

\section{The Theoretical Basis of the Interactive Teaching Model}

The foreign scholars' definition of interaction can be roughly divided into two types-broad and narrow. [3] In a broad sense, Malamah Thomas (1987) defines interaction as a process of interaction between people/objects through a series of behaviors. Ellis (1999) defines it as a social behavior of communication. H.D. Brown (2000) suggests that interaction refers to the exchange of ideas, 
feelings, or views between people who are then influenced by the exchange. From a narrow sense, Allwright (1991) put forward that interaction is the process of interplay between students or teachers and students in all kinds of forms, nature and degrees. [4] He pointed out that the effective use of interaction in class activities is the key to successful language teaching. Based on interaction, the teacher-guided and student-centered interactive teaching model encourages students to learn independently in an open and creative manner to form their own knowledge system. [5] Aiming at improving learners' pragmatic competence, the interactive teaching model establishes learners' principal status by multi-dimensional interaction, which helps to achieve independent learning, exploration learning and cooperative learning. It fully mobilizes the enthusiasm of learning and fosters learner autonomy and enhance learners' comprehensive ability of language use, thus it satisfies the objectives and requirements of foreign language teaching.

\section{The Application of Interactive Teaching Model in Teaching of College English Writing}

In the interactive teaching model of College English Writing, the writing process can be divided into three stages, as shown in Figure 1:

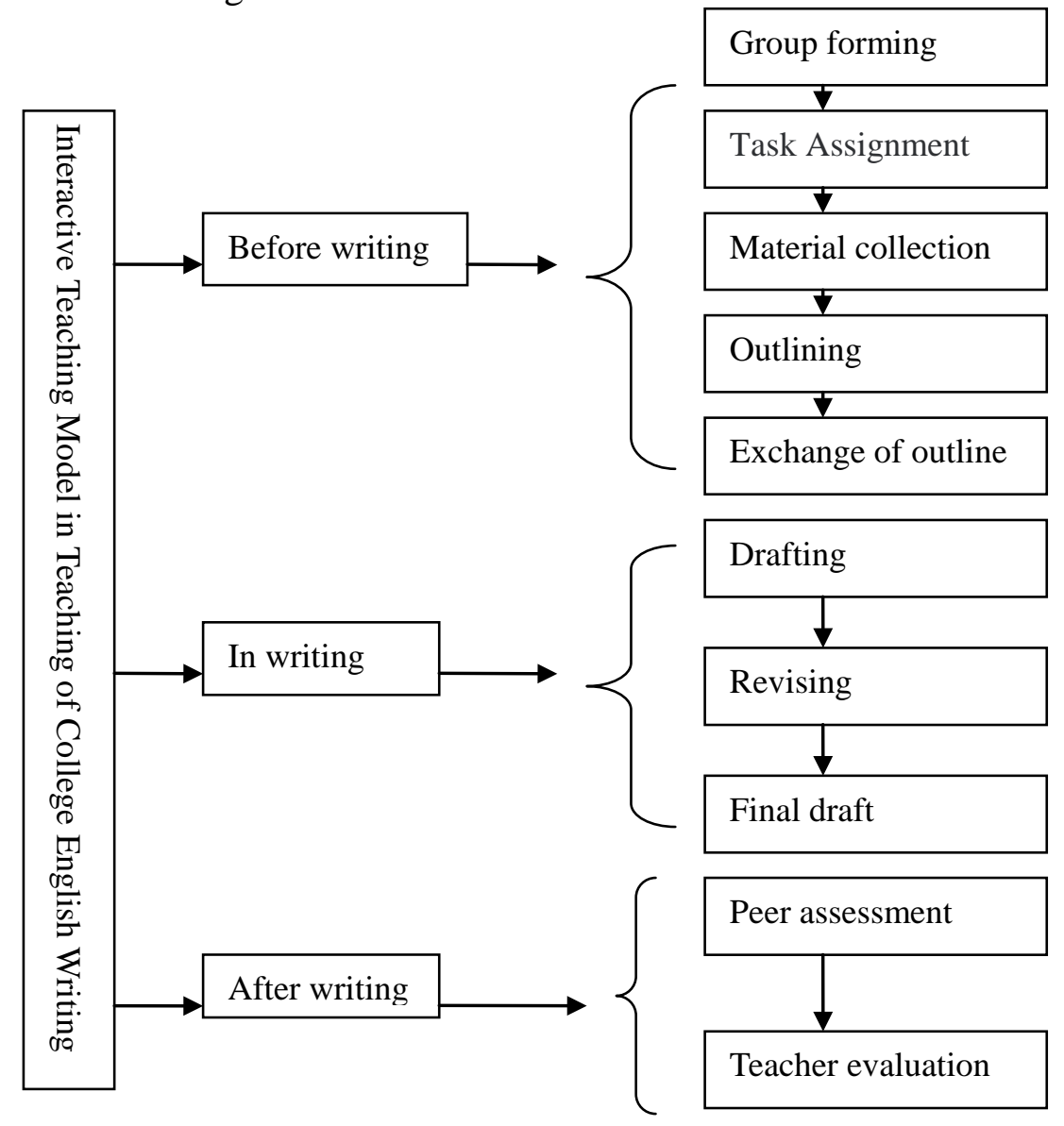

Figure 1 interactive teaching model

\subsection{Before Writing}

(1) Forming a Writing Group

After a period of observation and understanding of students, the teacher divides the class into 5 groups, each consisting of five members, considering students' learning ability and personality, the proportion of male and female students, and the principle of cooperative grouping. Then the role of team members is defined, including the team leader, the speaker, the recorder and examiners, so that all members can participate in interaction and cooperation. In addition, the seats are arranged into hub-and-spoke type in which the platform is in the center and all groups encircle the platform in a circular form, creating a relaxed learning atmosphere and facilitating the interactive and cooperative 
writing.

(2) Assigning Writing Task

In this stage the teacher should make students understand the topic of writing and arouse their writing interests. Therefore, teachers should carefully choose the topic of writing which should not only be closely related to the study and life of the students, but also let the students have the willingness to express.

(3) Collecting Materials

Brainstorming - teachers put forward questions related to the topic of composition for students to discuss, encourage each member to speak freely about the topic, and write down all relevant information. Then groups communicate and learn from each other to achieve a higher level of cooperative writing.

Clustering - various views after the brainstorming are classified for the sake of later use. This method gradually enables students to enter the phase of conception, and it requires them to pick, sort, analyze and integrate all kinds of scattered materials and information, so as to facilitate the subsequent clear presentation.

(4) Outlining

After brainstorming and classification, the students have already had their own ideas on the topic of writing. It's time to integrate the classified views and form an outline.

(5) Exchange of Outlines

Firstly, discuss outlines within the group, and vote for the best one in the group. Next, exchange and learn the excellent outlines selected by each group. Lastly, under the guidance and revision of the teachers, draw up the best outline together.

\subsection{In writing}

(1) Drafting

Students draft on the basis of the best outline selected by teachers and students through interaction and cooperation. At this point, students have nearly completed conception and begin to enter the expressing stage of writing. The draft is formed by arranging, combining and coding the text.

(2) Revising

Self-modification: students read through their drafts after the outline of writing, straighten up their writing ideas, and check the spelling, sentence patterns and punctuation correctly.

Peer revision: first, each group member transfers their revised composition to the other 4 members in the group for modification, which reflects within-group cooperation. Group members revise the draft according to four aspects: correct writing thought, clear logic, correct spelling and sentence patterns, and appropriate punctuation. Secondly, exchanges the revised composition in the group with other groups, and then revise again between two groups.

Teacher revision: teachers make final corrections on the basis of within-group and intergroup revision, and then return the revised composition to students.

(3) Final Draft

Students read feedback from teachers and classmates, modify and rewrite their composition, and finish final draft. The modification is made from four perspectives - view on writing, logic, word spelling, sentence structure and punctuation.

\subsection{After Writing}

(1) Peer Evaluation

First of all, evaluate the final draft among the group members according to the writing standards of CET-4. Each group votes for a best final draft, which reflects within-group cooperation. Secondly, the selected best final draft of each group is given to other groups to evaluate, which reflects intergroup cooperation.

(2) eacher Evaluation

On the basis of peer evaluation, 3 teachers who have participated in the correction of the CET- 4 examination make the final assessment by calculating the average score of 4 teachers. If the 
students are positive to accept this teaching method, and if it improves students' ability of writing and enhances the teaching effect of College English Writing, the application of interactive teaching in College English Writing class will contribute to the development of College English Writing teaching. If this teaching method is applied to teaching of College English Writing, teachers' teaching efficiency, students' learning efficiency and writing capability will be improved to a certain extent.

\section{Conclusions}

This study holds that a lack of interaction in current College English Writing class leads to the teachers' problems and confusion in teaching. Therefore, when interactive teaching is applied to college English cooperative writing, students' interest in writing is improved, writing experience has been changed, and their friendship with others has been more closely related. Interactive teaching effectively improves college students' performance of English writing. At last, this study proposes the application of interactive teaching model in College English Cooperative Writing, and gives some suggestions for future researches on College English Writing teaching.

\section{References}

[1] Stance-marking and stance-taking in Asian languages[J]. Shoichi Iwasaki. Journal of Pragmatics. 2015

[2] Guiding the reader (or not) to re-create coherence: Observations on postgraduate student writing in an academic argumentative writing task[J]. Helen Basturkmen, Janet von Randow. Journal of English for Academic Purposes. 2014

[3] Teacher assessment of grammatical ability in second language academic writing: A case study[J]. Heike Neumann. Journal of Second Language Writing. 2014

[4] Giving Feedback in Language Classes. Marilyn Lewis. 2007

[5] Teaching and Learning in the Language Classroom. Hedge T. 2002 